\title{
How many conidia are required for wound infection of apple plants by Neonectria ditissima?
}

\author{
M. Walter ${ }^{1}$, S. Roy ${ }^{2}$, B.M. Fisher ${ }^{3}$, L. Mackle ${ }^{4}$, N.T. Amponsah ${ }^{1}$, T. Curnow ${ }^{1}$, \\ R.E. Campbell ${ }^{1}$, P. Braun ${ }^{5}$, A. Reineke ${ }^{6}$ and R.W.A. Scheper ${ }^{3}$
}

${ }^{1}$ The New Zealand Institute for Plant \& Food Research Limited (PFR), Old Mill Road, RD 3 Motueka 7198, New Zealand

${ }^{2}$ Institut Technique Tropical, C/o Banamart, Bois Rouge, 97224 Ducos, Martinique

${ }^{3}$ PFR, Private Bag 1401, Havelock North, New Zealand

${ }^{4}$ Erzeugerring für Obst und Gemüse Straubing e.V., Wolfersdorf 3, 94522 Wallersdorf, Germany

${ }^{5}$ Hochschule Geisenheim University, Department of Pomology, 65366 Geisenheim, Germany

${ }^{6}$ Hochschule Geisenheim University, Department of Phytomedicine, 65366 Geisenheim, Germany

Corresponding author: monika.walter@plantandfood.co.nz

\begin{abstract}
A series of experiments, using potted plants in a glasshouse, detached laterals in the laboratory and trees in the field, were undertaken to study wound size and number of Neonectria ditissima conidia required to produce European canker infections on freshly-made branch wounds in the apple cultivars 'Royal Gala' and 'Scilate.' The wound types were needle and pin injuries, rasp wounds and pruning cuts. Spore concentrations from $10^{2}$ to $10^{6}$ conidia/ml, and two inoculation methods (droplet and mist), were used. Disease expression varied for the different assay types, probably due to the conduciveness for infection of the different incubation conditions. Overall, there was little effect on pathogen colonisation and lesion development based on injury type, inoculation method or spore concentration $>10^{3}$ conidia/ml. For freshly-made wounds, such as pruning cuts or rasp wounds, only three conidia were required for infection initiation in the glasshouse under highly conducive conditions, 12 conidia in the laboratory on detached shoots, and 10 to 30 conidia in the field.
\end{abstract}

Keywords: Neonectria galligena, Nectria galligena, European canker, apple, spore concentration, pruning wounds

\section{INTRODUCTION}

European canker, caused by the fungus Neonectria ditissima (formerly Neonectria galligena and Nectria galligena), is an important disease of apples in areas with frequent rainfall (Atkinson 1971, Beresford \& Kim 2011). This disease can result in the death of buds, shoots, spurs and branches of apple trees (English et al. 1979). In severe infections, the main trunks can become girdled with the disease, requiring the removal of entire trees. The pathogen produces ascospores in late winter and spring; and conidia in spring, summer, autumn and early winter. Sporulation, dispersal and infection occur during prolonged periods of high rainfall (Xu \& Butt 1996; McCracken et al. 2003). Neonectria ditissima can infect apple trees of all ages and varieties, entering trees 
through natural or artificial wounds, such as leaf scars in autumn (Crowdy 1952; Dubin \& English 1974), growth cracks and other scars that develop during spring and summer (Swinburne 1971), and pruning cuts (Xu et al. 1998).

Little is known about the minimum number of $N$. ditissima conidia required to cause disease symptoms on wounds in the field. Such information would assist in the determination of the risk of infection and the prediction of disease progression. A study was conducted to determine how many conidia of $N$. ditissima must be present on individual wounds for infection to take place and for symptoms of European canker to develop in apple trees in New Zealand.

\section{MATERIALS AND METHODS Glasshouse assay}

In early June 2009 in the winter, 15 potted 'Royal Gala' trees in a glasshouse were selected for this experiment. The glasshouse was not heated and had no artificial lighting. The trees, each with two 9-month-old shoots, were cut back using secateurs to ca $50 \mathrm{~cm}$, creating the pruning cuts. Both shoots of each tree were pruned $5 \mathrm{~mm}$ above a leaf or leaf scar. Inoculum of $N$. ditissima was prepared from a 2-day-old suspension of conidia $\left(10^{5} \mathrm{conidia} / \mathrm{ml}\right)$, in sterile distilled water containing $0.005 \%$ Tween 20 (Tween solution), harvested from field apple cankers from Motueka, New Zealand. The suspension had been stored overnight at $4^{\circ} \mathrm{C}$, but was warmed to room temperature before inoculation. A dilution series in Tween solutions was prepared from this suspension. Final conidial concentrations were $10^{5}, 10^{4}, 10^{3}$, $10^{2}$ and 0 conidia $/ \mathrm{ml}$, respectively. A $30-\mu$ droplet of inoculum was pipetted onto each wound of three replicate trees of the five conidial concentration treatments, within 5 min of wounding.

To optimise infection, misting was used to increase the relative humidity and to ensure free water was present on the surfaces of inoculated wounds for the first 3 days after inoculation: trees were misted for $15 \mathrm{~s}$ every $5 \mathrm{~min}$ for
24 hours, followed by $5 \mathrm{~s}$ every $5 \mathrm{~min}$ for 48 hours, then for $5 \mathrm{~s}$ every $15 \mathrm{~min}$ for 4.5 months.

The percentage conidial germination was determined by placing six drops of each of the two greater concentration conidial suspensions on glass microscope slides, immediately after inoculation. The slides were incubated at $20^{\circ} \mathrm{C}$ for $24 \mathrm{~h}$ in a humidity chamber, and the numbers of germinated and un-germinated conidia were counted using a microscope. A conidium was considered germinated when the germtube was at least the width of the conidium.

Wounds were assessed for canker symptoms 4.5 months after inoculation. The length $(\mathrm{mm})$ of each lesion was measured.

\section{Detached shoot assay}

In August 2015, 80 'Scilate'/Envy ${ }^{\mathrm{TM}}$ shoots were collected from the field and returned to the laboratory where all leaves (new growth) were removed and each shoot was placed in a glass vial filled with sterile distilled water. Each shoot was wounded 5 times using a needle $(0.4 \mathrm{~mm}$ diameter), pin $(1 \mathrm{~mm})$ or rasp $(3.7$ or $6.7 \mathrm{~mm})$. Wounds were placed between buds at least $5 \mathrm{~cm}$ apart and then inoculated with $N$. ditissima conidia collected from Motueka field cankers, as described above. Conidial concentrations were $0,1.2 \times 10^{3}$, $1.2 \times 10^{4}, 1.4 \times 10^{5}$ and $1 \times 10^{6}$ spores $/ \mathrm{ml}$. Inoculation was carried out using droplet inoculation $(10 \mu \mathrm{l})$ on top of each needle wound or on the side of each rasp wound. Shoots were each covered with a plastic bag and then incubated at $18^{\circ} \mathrm{C}, 16: 8 \mathrm{~h}$ light:dark. There were four replicate shoots per wound-inoculum concentration combination. Conidium viability was assessed as described above. Lesion formation was assessed (presence/absence) after 2 months.

\section{Field assays}

A row of 99 'Scilate' apple trees at a Plant \& Food Research trial site at Whakarewa Street, Motueka, New Zealand, was selected. The trees were grafted on 'M9' rootstocks and planted in winter 2014, and were free of European canker symptoms. Half the tree row was used in two repeat experiments, set 
up 14 days apart and are hereafter referred to as Field 1 and Field 2. A third field assay (Field 3) was also carried out in 2015. Neonectria ditissima inoculum was produced in sterile distilled water and checked for viability, as described above.

For Field 1 and Field 2, three branches per tree were selected randomly. Each branch was wounded three times in one of three ways: The smallest wound was caused by an injection needle $(0.4 \mathrm{~mm}$ diameter), the other two wounds were caused by a drawing pin (1 mm diameter) or a rasp $(6.7 \mathrm{~mm}$ diameter). The rasp wound served as a positive control to determine the maximum potential of infection at each inoculation time. Bigger wounds have been observed to be more susceptible to infection than smaller wounds (Amponsah et al. 2015). The depth of the wounds was ca $3.0 \mathrm{~mm}$. For the needle and pin injuries, tape was coiled around the instrument to create a barrier thereby ensuring the wound was less than $3 \mathrm{~mm}$ deep. Each branch had three injuries on the upper surface (middle section) ca $5 \mathrm{~cm}$ apart from each other, and at least $5 \mathrm{~mm}$ apart from leaf or bud positions.

In Field 1, four different concentrations of inoculum were used $\left(0,3 \times 10^{3}, 3 \times 10^{4}, 1.5 \times 10^{5} \mathrm{~N}\right.$. ditissima conidia/ml), and wounds were inoculated on the 26 March 2015. In Field 2, inoculation was carried out on 16 April 2015 with conidial concentrations of $0,2.4 \times 10^{4}, 7 \times 10^{4}, 1.5 \times 10^{5} \mathrm{~N}$. ditissima conidia/ml. A misting bottle was used for inoculation, with the nozzle calibrated to deliver ca $0.1 \mathrm{ml}$ of spore suspension at each single operation. Each branch was inoculated with 4-5 spray bottle operations over the wounds, releasing up to $0.5 \mathrm{ml}$ of spore suspension. This caused a fine layer of droplets on the inoculated branches without run-off. The average application size was ca 1472.3 conidia $/ \mathrm{mm}^{2}$ as measured by misting conidial suspension $\left(1.5 \times 10^{6}\right)$ onto glass slides.

In the Field 3 experiment, $0,1 \times 10^{3}, 1 \times 10^{4}$, $1 \times 10^{5}$ and $1 \times 10^{6}$ conidia/ml were used (droplet $10 \mu \mathrm{l})$ to inoculate the different wound treatments (no wound, $0.4-\mathrm{mm}$ needle, $1-\mathrm{mm}$ pin or $5-\mathrm{mm}$ rasp wound) on 21 September 2015. For each rasp wound, the droplet was placed at the edge of the wound. There were three wounds per shoot, but in this experiment, half the shoots were each covered with a green tree guard plastic sleeve (PGG Wrightson Ltd), but left open on either side for ventilation. Sleeves were removed at the first assessment (16 November 2016). Covered and uncovered shoots were paired on a tree for each wound-inoculum treatment combination with four replicate trees per treatment.

In Fields 1 and 2, assessments were carried out 2 months after inoculation, by scoring the inoculation site with 1 = wound only visible, 2 = a wound reaction visible, 3 = lesions visible but not certain if this is a European Canker lesion, and $4=$ European Canker lesion distinctly visible. After the visual rating, the shoots were each cut close to the main trunk and the wound was treated immediately with a commercial pruning paint $\left(\right.$ Greenseal $\left.^{\mathrm{Tx}}\right)$. The shoots were brought back to the laboratory for further processing. All leaves were removed and only the treated section of each shoot was recovered for dissection and isolation onto apple sap amended water agar (ASAWA, Amponsah et al. 2014). The wood pieces were each sterilized by flaming after being dipped in $70 \%$ ethanol for ca 30 s. For further isolation, the bark around each inoculation/wound site was carefully removed using a sterile scalpel. This exposed the discoloured or symptomless tissues underneath. From the edge of the wound and/or visible lesions, three to five small tissue pieces were cut aseptically and placed onto ASAWA in Petri plates. The plates were incubated on a laboratory bench $\left(20^{\circ} \mathrm{C}\right)$ for $2-3$ weeks and presence/absence of $N$. ditissima sporodochia and conidia was assessed using a microscope $(\times 200$ magnification $)$. This was done with a plastic well (10 $\mathrm{mm}$ diameter) placed over each wood segment in the Petri plates. The wells were flooded with distilled water (ca 60-100 $\mu \mathrm{l}$ ), any conidia were allowed to dehisce for a few minutes, and then 10- $\mu$ l aliquots were scanned under the microscope for presence/absence of $N$. ditissima conidia.

For the Field 3 experiment, visual assessments for European canker symptoms (presence/ absence) were carried out on 16 November 2015, 20 January 2016 and 16 February 2016. At the each assessment, shoots with one or more lesions were 
removed to prevent secondary infections. The cut area of each shoot was treated with pruning paint.

\section{Statistical analyses}

For the glasshouse assay, transformation of lesion size and disease incidence data were not required, as the data were normally distributed and had homogeneous variances. Analysis of Variance (ANOVA) and Fisher's Protected Least Significant Differences of Means (LSD, $\alpha=0.05$ ) were used to determine statistical differences in disease incidence among treatments. Restricted Maximum Likelihood (REML) was used to determine statistical differences in mean lesion sizes among treatments using GenStat version 12 (VSNi Ltd, Hemel Hempstead, UK). Analyses of the other experiments were performed using Minitab ${ }^{\star}$ version 16 or 17.2.1. Tests used were: Pearson correlation, two sample T-test, analyses of variance (General linear model), and Fisher Pairwise Comparisons. For easy visualization of results and comparison of trends among experiments, disease data are presented as percentage lesion expression.

\section{RESULTS \\ Conidium germination}

In the glasshouse assay, conidium germination after $24 \mathrm{~h}$ at $20^{\circ} \mathrm{C}$ was $67 \%$. In the detached shoot experiment, germination was $79 \%$. In Field 1, 2, and 3 experiments, germination was 62,80 and $83 \%$ respectively.

\section{Canker development in the glasshouse assay}

Four and a half months after inoculation, lesions were visible on all shoots that were inoculated with $10^{4}$ or $10^{5}$ conidia/ml (Table 1 ). Five of the six shoots inoculated with $10^{3}$ conidia/ml had canker symptoms, while the sixth wounded shoot had suspected symptoms at that time, which subsequently developed into typical symptoms 9.5 months after inoculation. Disease incidence was less when shoots were inoculated with $10^{2}$ conidia/ml compared with $10^{4}$ or $10^{5}$ conidia $/ \mathrm{ml}$ $(\mathrm{P}<0.001$, Table 1$)$. At $10^{2}$ conidia/ $\mathrm{ml}$, four of the six shoots had canker symptoms, while two wounds had healed without canker symptoms. All wounds treated with Tween solution only (the control) healed without symptoms.

The lesions varied in length from $6 \mathrm{~mm}$ to $24 \mathrm{~mm}$, but there was no statistically significant effect of inoculum concentration on lesion length $(\mathrm{P}=0.266$, Table 1). Shoots of the negative control trees did not have any lesions, but most displayed $1 \mathrm{~mm}$ of

Table 1 Mean lesion length (predicted mean in brackets), and disease incidence (percentage of pruning wounds with canker symptoms) on potted 'Royal Gala' trees in a glasshouse, 4.5 months after inoculation with conidia of Neonectria ditissima. Four different concentrations of conidia were compared with a Tween 20 solution $(0.005 \%)$ as control.

\begin{tabular}{lcrrrr}
\hline $\begin{array}{l}\text { Inoculum } \\
\text { concentration }\end{array}$ & $\begin{array}{l}\text { Average number of } \\
\text { conidia/ wound } \\
(\mathbf{3 0}-\boldsymbol{\mu} \text { L droplet) }\end{array}$ & $\begin{array}{c}\text { Mean lesion length } \\
(\mathbf{m m})\end{array}$ & $\begin{array}{c}\text { Disease incidence } \\
(\%)\end{array}$ \\
\hline $10^{5}$ conidia/ml & 3,000 & 12.0 & $(12.5)$ & $\mathrm{a}$ & $100 \mathrm{a}$ \\
$10^{4}$ conidia/ml & 300 & 9.7 & $(9.7)$ & $\mathrm{a}$ & $100 \mathrm{a}$ \\
$10^{3}$ conidia/ml & 30 & 13.6 & $(13.0)$ & $\mathrm{a}$ & $83 \mathrm{ab}$ \\
$10^{2}$ conidia/ml & 3 & 18.0 & $(19.0)$ & $\mathrm{a}$ & $67 \mathrm{~b}$ \\
Control & 0 & 0.8 & & 0 & $\mathrm{c}$ \\
\hline
\end{tabular}

Means accompanied with the same letter within each column are not significantly different (predicted mean lesion size $\mathrm{P}=0.266$ (REML); disease incidence $\alpha=0.05, \mathrm{P}<0.001$ (ANOVA)). 
natural dieback without any canker symptoms.

\section{Detached shoot assay}

Wound size, inoculum concentration and the interaction between these treatments affected $(\mathrm{P}<0.001)$ lesion development on detached shoots. No lesions developed in the water controls for any wound size. In contrast 30\%, 52\%, 66\% and $50 \%$ of the $0.4,1,3.7$ and $6.7 \mathrm{~mm}$ wounds respectively developed symptoms during the 2-month incubation period, irrespective of conidial concentration. Over all wound sizes, the conidial concentration effect was demonstrated by $0,44,53,78$ and $74 \%$ of wounds developing symptoms for $0,1.2 \times 10^{3}, 1.2 \times 10^{4}, 1.4 \times 10^{5}$, and $1 \times 10^{6}$ conidia/ml inoculations respectively. The interaction between conidial concentration and wound size was only observed in the largest wound $(6.7 \mathrm{~mm})$, plus an unexpected decrease
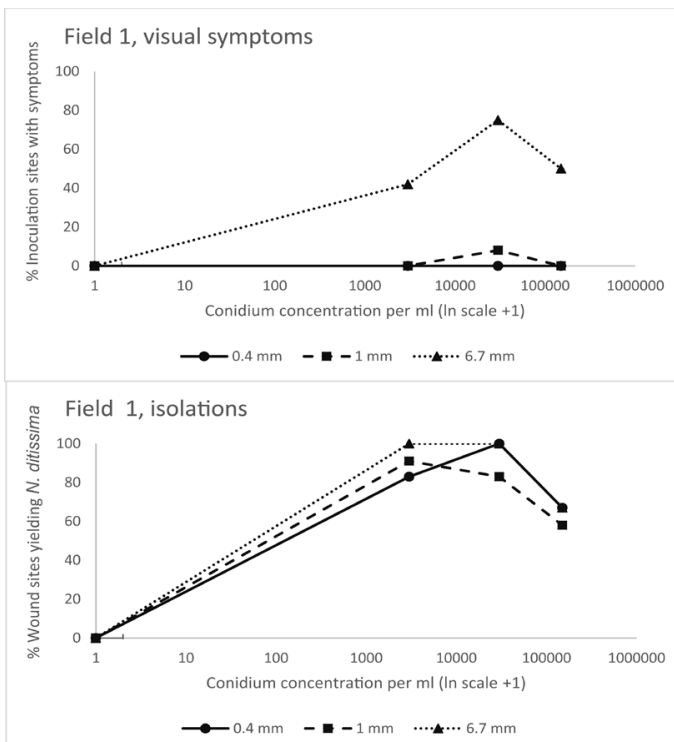

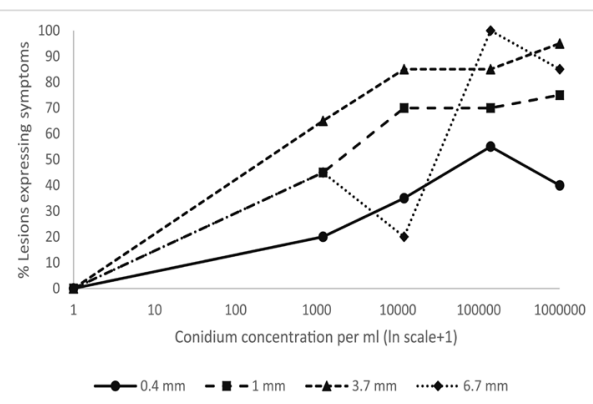

Figure 1 Percentage of total inoculated wounds expressing symptoms when inoculated with Neonectria ditissima conidium concentrations varying in wound size ( $\mathrm{mm}$ diameter) in detached 'Scilate' apple shoots $(\mathrm{n}=20$ wound/ concentration combinations) 2 months after inoculation. The average number of conidia/ wound were $12,120,1,400$ and 10,000 for, respectively, the $1.2 \times 10^{3}, 1.2 \times 10^{4}, 1.4 \times 10^{5}$, and $1 \times 10^{6}$ conidia/ml concentrations.
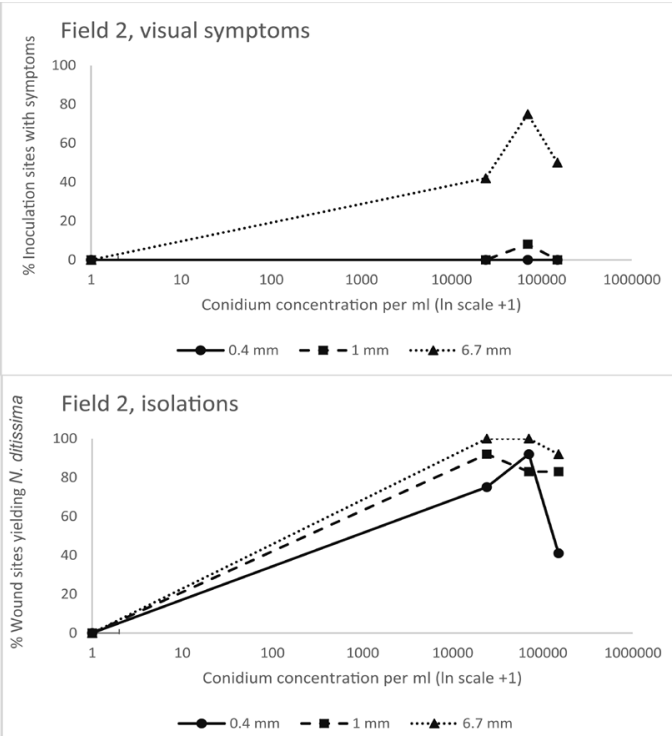

Figure 2 Mean percentages of total inoculated wounds expressing symptoms 2 months after inoculation of 'Scilate' apple shoots in situ, as affected by Neonectria ditissima conidium concentration and wound size (mm diameter) in the Field 1 (left graphs) and Field 2 (right) experiments. European canker symptoms (top graphs) and tissue isolations from the inoculation sites (bottom) are shown. There were three wounds per shoot, with $\mathrm{n}=8$ shoots per wound/concentration treatment combination. Inoculations were carried out using a hand-held misting bottle. The average number of conidia $/ \mathrm{mm}^{2}$ were estimated to be 30,300 , and 1,470 for the $3 \times 10^{3}, 3 \times 10^{4}$, and $1.5 \times 10^{5}$ conidia/ml concentrations respectively in Field 1; and 230, 690, and 1470 spores for the $2.4 \times 10^{4}, 7 \times 10^{4}$, and $1.5 \times 10^{5} \mathrm{conidia} / \mathrm{ml}$ concentrations respectively in Field 2. 
in the proportions of lesions that developed with the middle conidial concentration (Figure 1).

\section{Field experiments}

In Fields 1 and 2, the effects of wound size and inoculum concentration were statistically significant $(\mathrm{P}<0.001)$ in relation to percentage sites with symptoms. There were no significant interactions observed between these treatments $(\mathrm{P}>0.05)$. The non-wounded inoculations yielded neither visual lesions, nor was isolation of the pathogen from the inoculation sites successful. There were few visual symptoms in the needle and pin wounds after 2 months, but there were in the rasp wounds (Figure 2). However, tissue isolations showed that colonisation by the pathogen had occurred (Figure 2). This was similar for the different wounds and conidial concentrations. For these isolations, the only statistically significant differences were the presence and

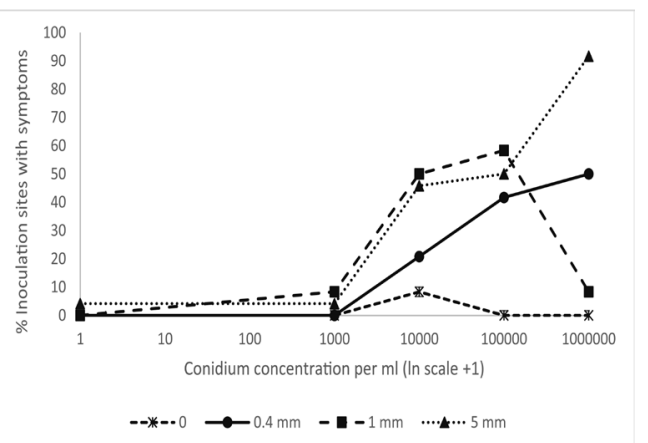

Figure 3 Percentage of total inoculated wounds expressing symptoms on 'Scilate' apple shoots in situ as affected by Neonectria ditissima conidium concentration and wound size ( $\mathrm{mm}$ diameter) treatments, 4 months after inoculation in the Field 3 experiment. There were three wounds per shoot, with $n=8$ shoots per wound/concentration treatment combination. The average number of conidia/wound were $0,10,100,1,000$ and 10,000 spores for the $0,10^{3}, 10^{4}, 10^{5}$, and $10^{6}$ conidia $/ \mathrm{ml}$ concentrations respectively. absence of conidia (irrespective of concentration), as well as between wounded and non-wounded treatments, irrespective of wound size $(\mathrm{P}<0.001)$.

In Field 3, covering the shoots with plastic sleeves did not affect lesion development $(\mathrm{P}=0.551)$, or cause any interactions with wound size and conidial concentration $(P>0.248)$, and was therefore ignored in the further data analyses. The non-wounded inoculations yielded only one shoot with infection from the $10^{4}$ conidia/ $\mathrm{ml}$ concentration and therefore these data are not presented. The water inoculations yielded two lesions, both from 5-mm rasp wounds. There were statistically significant wound size, conidial concentration and wound/concentration interaction effects $(P>0.001$, Figure 3$)$. The interaction resulted from the low number of lesions formed (three in total) after the $1 \mathrm{~mm}$ wound and $10^{6}$ conidia $/ \mathrm{ml}$ inoculation treatment.

\section{DISCUSSION}

The five experiments described here all showed that a range of $N$. ditissima conidial concentrations affect European canker symptom development in apple trees. This is not particularly surprising as many diseases and successful infections are dependent on pathogen inoculum concentration. What is noteworthy, however, is the low conidial concentrations required for successful infection and symptom development.

Dubin \& English (1974) reported that 50 conidia were required for infection of apple leaf scars. In our study, as few as three conidia produced infections of pruning cuts in the glasshouse, where the most favourable conditions occurred for infection and disease development in these five experiments. Free moisture and high relative humidity (Xu et al. 1998; Latorre et al. 2002), large wounds (pruning cuts) and stressed potted trees with water around the roots ("wet feet" based on the intensive, regular misting) of a very susceptible cultivar ('Royal Gala') were used. All infections were allowed to develop into cankers over a 9-month period (data not shown). In the detached shoot assay and Field experiments, 12 and 10-30 conidia respectively 
facilitated infections and symptom expression in 'Scilate' wood, although many inoculated wounds did not develop symptoms. This was possibly because they escaped infection, or because disease had not expressed in the 2-4 months of observations. The lack of symptom expression but establishment of infections was demonstrated in Fields 1 and 2 with the successful re-isolation of the pathogen (Figure 2). The detached shoot assay was conducted in the absence of high humidity at $18^{\circ} \mathrm{C}$. The field experiment was conducted under natural conditions and the use of plastic covers, and hence increases in humidity did not affect the number of European canker lesions formed in Field 3. This indicated that adequate moisture for infection was present (Latorre et al. 2002) at the time of inoculation with or without the plastic covers. The data of Fields 1 and 2 also indicated that the rate of infection (based on the tissue isolations) is dependent on neither wound size nor conidial concentration. However, the rate of symptom expression (based on visual assessment) was higher in larger wounds and, to a lesser extent, with greater inoculum concentrations. This effect may have levelled out over time, with infected wounds being allowed to develop. The effect of wound size/type has been described by Amponsah et al. (2015), showing that different natural wound types facilitate different rates of symptom development (i.e. the time required from infection to symptom expression). Amponsah et al. (2015) studied natural wounds (leaf scars, picking wounds) and artificial pruning cuts, with pruning cuts yielding the most European canker lesions. The experiments described here were done with artificial wounding, and therefore are comparable to the type of injury arising from pruning cuts.

The glasshouse study also demonstrated that once the infection expresses, further lesion development is independent of the original inoculum concentration. At the point of symptom expression, sufficient fungal biomass has probably established for symptom development. It is likely that inoculum concentration and wound type both affect the speed and proportion of tissue colonisation, and symptom expression occurs once a biomass threshold has been met.
While rate of infection and lesion development are also subject to other biotic and abiotic factors (Swinburne 1975; Weber 2014), conidial concentration and initial pathogen biomass might play roles in the length of the quiescent period from infection to disease expression. According to McCracken et al (2003), N. ditissima infections can remain symptomless for 3 years or more. The biomass-latency-quiescent relationships and biotic and abiotic drivers that determine infection, establishment and symptom expression for this pathosystem require further elucidation.

The number of conidia required to infect leaf scars or picking wounds cannot be deduced from this research, as these wounds each have an abscission layer that may be protective. Dubin \& English (1974) determined that five conidia placed at a leaf scar of a potted 'Red Delicious' tree were insufficient to cause disease symptoms. In their study, 50 conidia/leaf scar resulted in nearly $20 \%$ of leaf scars with cankers, while 5,000 conidia/leaf scar were required to achieve more than $80 \%$ of leaf scars with symptoms. Similarly, Scheper \& Fisher (2010) determined that 40\% of 'Royal Gala' leaf scars developed cankers after inoculation with 800 viable conidia per leaf scar. This indicated that the number of conidia required to infect leaf scars is greater than for pruning cuts, and that leaf scars can escape symptom development, and possibly infection, even when inoculated with large numbers of conidia.

This research emphasises the importance of wound treatments to prevent infection with $N$. ditissima, as the presence of few conidia on artificial injuries in susceptible apple varieties can result in infection and disease development. Wound dressing paints effectively protect pruning wounds from $N$. ditissima infection (Scheper et al. 2008) and should be used in commercial orchards.

\section{ACKNOWLEDGMENTS}

This research was supported by New Zealand's Foundation for Research, Science and Technology (Contract CO6X0810, Low Impact Disease Control). We thank Duncan Hedderley, Jaap Scheper and Peter Alspach for help with the statistical analyses. 


\section{REFERENCES}

Amponsah NT, Walter M, Scheper RWA 2014. Agar media for isolation of Neonectria ditissima from symptomatic and asymptomatic apple tissues and production of infective conidia. New Zealand Plant Protection 67:116-122.

Amponsah NT, Walter M, Beresford RM, Scheper RWA 2015. Seasonal wound presence and susceptibility to Neonectria ditissima infection in New Zealand apple trees. New Zealand Plant Protection 68:250-256.

Atkinson JD 1971. Diseases of tree fruits in New Zealand. Wellington, New Zealand, A.R. Shearer, Govt Printer.

Beresford RM, Kim KS 2011. Identification of regional climatic conditions favorable for development of European canker of apple. Phytopathology 101: 135-146.

Crowdy SH 1952. Observations on apple canker IV: the infection of leaf scars. Annals of Applied Biology 39: 569-580.

Dubin HJ, English H 1974. Factors affecting apple leaf scar infection by Nectria ditissima conidia. Phytopathology 64: 1201-1203.

English H, Dubin HJ, Schick FJ 1979. Chemical control of European canker of apple. Plant Disease Reporter 63(12): 998-1002.

Latorre BA, Rioja ME, Lillo C, Muñoz M 2002. The effect of temperature and wetness duration on infection and a warning system for European canker (Nectria galligena) of apple in Chile. Crop Protection 21: 285-291.

McCracken AR, Berrie A, Barbara DJ, Locke T, Cooke LR, Phelps K, Swinburne TR, Brown AE, Ellerker B, Langrell SRH 2003. Relative significance of nursery infections and orchard inoculum in the development and spread of apple canker (Nectria galligena) in young orchards. Plant Pathology 52(5): 553-566.
Scheper RWA, Fisher BM 2010. Comparing methods to determine European canker resistance in apple tree accessions. New Zealand Plant Protection 63: 280

Scheper RWA, Stevenson OD, Beresford RM 2008. Protecting wounds from European canker (Neonectria ditissima) infection of apple in winter and autumn. In: Porta-Puglia A, Gonthier P ed. 9th International Congress of Plant Pathology. Turin, Italy, Journal of Plant Pathology. Pp. S2.368.

Swinburne TR 1971. The seasonal release of spores of Nectria galligena from apple cankers in Northern Ireland. Annals of Applied Biology 69: 97-104.

Swinburne TR 1975. European canker of apple (Nectria galligena). Review of plant pathology 54: 787-799.

Weber RWS 2014. Biology and control of the apple canker fungus Neonectria ditissima (syn. N. galligena) from a Northwestern European perspective. Erwerbs-Obstbau: DOI 10.1007/s10341-014-0210-x.

Xu X, Butt DJ 1996. Tests of fungicides for postgermination activity against Nectria galligena, causal agent of canker and fruit rot of apple. Crop Protection 15(6): 513-519.

Xu X, Butt DJ, Ridout MS 1998. The effects of inoculum dose, duration of wet period, temperature and wound age on infection by Nectria galligena of pruning wounds on apple. European Journal of Plant Pathology 104(5): 511-519. 